\title{
Research on Farmer Education Countermeasures in the New Era
}

\author{
Lian He \\ Yangtze Normal University, Chongqing, 408100
}

Keywords: Farmer Education, New Era, Skills

\begin{abstract}
Implementing the rural revitalization strategy is an important measure for us to implement the new development concept and win the decision to build a well-off society in an all-round way. The revitalization of rural areas is very rich. It includes both rural economic revitalization, social revitalization and cultural revitalization, as well as rural governance system innovation and ecological civilization construction. It is a comprehensive concept of overall revitalization and needs to be comprehensively promoted in three dimensions. In other words, rural revitalization is not only a simple increase in the total amount of rural material wealth, but also reflected in the improvement of rural productivity, adjustment of production relations, economic infrastructure development and superstructure reform, etc., reflected in the overall transformation and upgrading of rural areas. Not only must we advance in terms of specific goals, but also advance in the way to achieve the goals and motivation. This kind of transformation, upgrading and promotion cannot be separated from the support of education. It cannot be separated from the transformation of peasants' ideological concepts and the improvement of comprehensive quality. It is inseparable from the exemplary and leading role of new professional farmers. Under the premise that many rural areas are not enough to attract and retain high-level talents, scientific and systematic education of new professional farmers can provide strong talent guarantee for the transformation and upgrading of agriculture.
\end{abstract}

\section{Introduction}

The report of the 19th National Congress of the Communist Party of China pointed out that it is necessary to adhere to the priority development of agriculture and rural areas, accelerate the modernization of agriculture and rural areas, and make major arrangements for launching a new era of building a new era of socialist modernization. Since the 18th National Congress of the Communist Party of China, in the process of promoting China's modernization drive, with the continuous strategic advancement of the "four modernizations", China's agricultural and rural development has made brilliant achievements. However, due to the differences in development conditions and development capabilities, urban and rural development has always been uncoordinated and unbalanced. For a long time, agricultural and rural modernization has always been the weak link and shortcoming of building socialist modernization in an all-round way. The report of the 19th National Congress pointed out that the decision to complete a well-off society in an all-round way is to fill the shortcomings of the rural areas. To promote the modernization of agriculture and rural areas, it is urgent to accelerate the cultivation of modern agricultural leading talents and highly skilled talents with new ideas and knowing science and technology. Therefore, focusing on the development of new-type vocational peasant education and training that is compatible with modern agriculture is not only an effective means of enriching the people with knowledge, enriching the people with science and technology, but also the only way to build a modernization of agriculture and rural areas.

\section{Misunderstandings in the thinking and practice of peasant education}

At present, the research on training and education of new professional farmers mostly focuses on the dilemma and path research, focusing on the analysis of the problems and solutions of the new professional peasant education, and grasping the research of new professional peasant education 
from the perspective of correct ideas and scientific thinking. less. Comrade Xi Jinping pointed out that mastering and applying Marxist standpoints and methods to study and solve China's practical problems is an important indicator of our good work. In practice, some doubts and confusions encountered in the new professional peasant education, some mistakes and deficiencies, the fundamental reason lies in the lack of correct understanding and understanding of the new professional peasant education, thinking more or less in thinking Misunderstanding.

Marxist historical materialism holds that the fundamental force that promotes the participation of social individuals in practical activities is the needs of human beings. Therefore, the needs of the new professional farmers are the starting point and internal motivation of their participation in education. The stronger the endogenous needs, the stronger the internal drive of learning, the more effective, stable and sustainable the learning, the better the learning effect. However, judging from the current educational goal setting of the new professional farmers, the exhibitors are more willing and self-righteous. The wishful thinking is expressed in the enthusiasm of educational sponsors, active planning and arrangement, and emphasizes that the party and the government hope that through education, farmers will be able to meet the comprehensive quality of modern social development and promote the all-round development of rural areas. Too much emphasis on the country's educational requirements, ignoring "passion, enthusiasm is the essential strength of people's strong pursuit of their own objects", easily lead to new passive behavior of the new professional farmers to develop passive and even cold resistance; self-righteous It is manifested in the fact that education deviates from the needs of new professional farmers, neglects the learning patterns and learning characteristics of new professional farmers, ignores the differentiation and differences in their internal quality, and provides courses for "top-down" education and content. Lead to lack of specificity and effectiveness of education. In fact, the needs of farmers' own development and the requirements of the party and the state for the development of farmers are not in conflict. However, the subjectivity and coercion embodied in the educational goal is not conducive to the realization of the common integration of the individual development of the peasant and the overall development of the country through education.

Many people think that the new type of occupational peasant education mainly refers to vocational education focusing on the popularization of agricultural practical technology, such as food cultivation, aquaculture, and horticultural training. In fact, no matter from the development of the countryside or the evolution of the peasants, this understanding is extremely biased. From the perspective of rural development, before the founding of the People's Republic of China and before the reform and opening up, peasant education was mainly focused on the cultural education of "literacy". From the reform and opening up to the 1980s, peasant education was mainly vocational and technical training, and from the 1980s. From the end of the 1990s, the main focus was on academic education and vocational and technical training. Since the beginning of the 21st century, peasant education has been reflected in peasant vocational education and vocational and technical training as well as lifelong education. From the perspective of the evolution of farmers, the current farmers are mainly divided into traditional farmers and new professional farmers. The new type of professional farmers can be said to be farmers based on the current social development trend, oriented to urbanization, industrialization, informationization and farmers' professionalization. Compared with traditional farmers, they should not only have culture, technology, good management, but also management. They should also have a broader vision and a strong sense of mission for sustainable development of agriculture and rural areas, with more advanced development concepts and more. Comprehensive basic qualities, such as green, innovation, integrity, openness and other new concepts; development of agricultural industrialization, characteristic agriculture and cooperative organizations and other export-oriented capabilities. The development of rural areas and the development of new-type professional farmers determine that new-type vocational farmer education should not only be vocational education, but should cover many aspects, such as cultural knowledge education, professional spirit cultivation, science and technology education, legal education, ecological education, entrepreneurship education. Wait. However, at present, the education of new professional farmers in many places in China is more 
focused on vocational and technical training. The content of education lags behind vivid and vivid practice and development of the times.

\section{Path choices for peasant education}

Based on the continuous development of social practice and the understanding of the learning needs of the main body, "realize" the education of new professional farmers. Marxist philosophy has a clear practicality and opposes the absoluteization and immobilization of the understanding of objective things and people. The same is true of the education of new professional farmers. With the passage of time and the advancement of the times, objective and actual changes have taken place, and the understanding of peasant education should be continuously deepened and expanded. Because education is always "closely related to change, it is always adapting people to higher-level things, not to the status quo of things". At present, agriculture has changed from a closed self-sufficient to an open market. From farming to production management, from traditional human investment to relying on technology and capital investment, changes in times and practices require new professional farmers to It should have a modern sense of responsibility, openness and innovation, and advanced concepts. It determines the education content setting can no longer stay in the narrow new production skills of the new professional farmers to obtain survival information, but to meet the pre-production, post-production and post-production of agriculture. And the perspective of the entire industry chain, extending it to a broader perspective of democracy and rule of law education, agricultural technology innovation education, business management education. In addition, Marxism believes that the subject of practice is the most active and autonomous factor in practical activities, and it plays an important role in regulating and controlling the initiation and cessation of practical activities. Comrade Xi Jinping also pointed out that "the economic and social development of rural areas, in the final analysis, the key lies in people. It is necessary to pass rich peasants, raise peasants, support peasants, and make peasants become decent jobs." New professional peasants not only need economics. Abundance, identity, and personal dignity. They not only need vocational and technical education, but also need to accept other educational content to meet their needs for sustainable development, thus realizing the transformation of new professional farmers from identity to occupation, from part-time to professional, from traditional agriculture to modern agricultural management. Therefore, in the new era, the new professional peasant education curriculum should take the initiative to consider the educational needs of the new professional peasants, select individualized teaching content according to the characteristics of the new professional peasants, select and combine knowledge points according to their knowledge needs, according to the local agricultural economic development. The situation adjusts the curriculum to change the misplacement of external supply and internal demand for education.

Cultivating new professional farmers is not a simple education and training task. Because of its comprehensive nature, education has different educational resources and educational methods. These resources and methods are not isolated and irrelevant, but closely linked and interlinked. From the perspective of education implementation, we need to build high-minded views based on the universal connection of Marxism, use strategic thinking, holistic thinking and systematic thinking to coordinate ministries such as the Ministry of Agriculture, the Ministry of Education, the Ministry of Finance, and the Office of Poverty Alleviation to form a consensus and integrate education. Resources, focusing on the overall consideration rather than individualism. At the same time, it is necessary to encourage social forces to participate in the cultivation of new professional farmers, and to build a multi-teaching network in which rural vocational education leads and social strength participates actively. From the perspective of educational methods, it is necessary to comprehensively use on-the-spot training, centralized classes, household guidance, field consultation and other methods to publicize and popularize advanced agricultural practical technologies and extensively popularize popularized training. At the same time, build a specialized training platform with agricultural radio and television schools and farmers' science and technology education and training centers as the main body or support, give full play to the agricultural college education and training system, agricultural research and education training system, agricultural 
technology extension education and training system, Agricultural Broadcasting School The role of the training system is to develop a new type of professional peasant education and training system that is widely participated by middle and higher agricultural colleges, research institutes, agricultural technology extension service institutions, agricultural parks, agricultural enterprises, farmers' professional cooperatives, and specialized industrial villages. Agricultural cooperation, "local proximity" theoretical teaching and on-site teaching and other educational methods, actively promote "field classroom", "mobile classroom", "school teaching + agricultural base internship", "field training and agricultural production guidance" and other multi-level, multi-form Education and training. For example, in Jingde County, Anhui Province, a new type of professional peasant was organized to study at the industrial base. The new professional peasant training in Yixian County of Anhui Province went from the classroom to the field. The "menu-style" and “order-based” training in Hunan Xiangxiang was a good practice education model. .

\section{Conclusion}

As long as we raise awareness of the importance and necessity of education and training activities, keep abreast of the needs of new rural areas and farmers, and expand in the breadth and depth of training to achieve breakthroughs in the quantity and quality of training, we are worthy of the people The mission of adult education will go further and better.

\section{Acknowledgment}

Project: Social Science Project in Fuling District: "Research on the Observation and Evaluation of Citizens' Socialism Core Value in Fuling District"

Project Number: SKGHHQL201804

\section{References}

[1] Yang Zhi. The Motive Force and Dimension of Peasant Education Development in China_Based on the Perspective of Demography[J]. Vocational and Technical Education, 2015 (7): 65 - 69.

[2] Wang Liubiao. Cultivating new professional farmers needs to focus on five aspects [J]. Rural Workletter, 2016 (2): 53 - 55.

[3] Yang Chengming, Zhang Mianhao. Study on the cultivation of new professional farmers in China under the threshold of many importance[J]. Vocational and Technical Education, 2014 (28): $76-82$.

[4] Chen Yu, Chen Junliang. Exploration of the cultivation of professional farmers under the background of new urbanization [J]. Rural Economy and Technology, 2014 (1): 189.

[5] Huang Jing, Hou Wenhua. Analysis of the Necessity of Farmer Education in China and Government Responsibility [J]. Journal of Yuncheng University, 2013 (6): 19. 